\title{
Óleos essenciais no controle da pinta bacteriana e na ativação de respostas bioquímicas em tomateiro
}

\author{
Érika Oliveira da Silva ${ }^{1}$, Eduardo Alves ${ }^{2}$, Thiago Costa Ferreira ${ }^{1}$, Carlos Alberto Cavalcante de Albuquerque ${ }^{1}$
}

\author{
${ }^{1}$ Universidade Estadual Paulista/FCA, R. Dr. José Barbosa de Barros, 1780, 18610-307, Botucatu, SP. ${ }^{2}$ Universidade Federal de Lavras, Departamento \\ de Fitopatologia, 37200-000, Lavras, MG. \\ Autor para correspondência: Érika Oliveira da Silva (erikaagro@gmail.com) \\ Data de chegada: 15/03/2016. Aceito para publicação em: 13/03/2017.
}

$10.1590 / 0100-5405 / 2167$

\section{RESUMO}

Silva, E.O.; Alves, E.; Ferreira, T.C.; Albuquerque, C.A.C. Óleos essenciais no controle da pinta bacteriana e na ativação de respostas bioquímicas em tomateiro. Summa Phytopathologica, v.43, n.3, p.212-217, 2017.

O objetivo deste trabalho foi avaliar o efeito dos óleos essenciais (OEs) de Cymbopogon sp. (Critonela - CI) e Cymbopogon citratus (Capim limão $\mathrm{CL})$ na redução da pinta bacteriana (Pseudomonas syringae pv. tomato- Pst) e na ativação de algumas respostas bioquímicas de defesa em tomateiro. Foi realizado um teste in vitro para avaliar a presença ou ausência do halo de inibição de Pst pelos OEs, um experimento in vivo para avaliar a melhor concentração desses dois óleos para o controle da pinta bacteriana e um experimento para avaliar o potencial desses óleos e do acibenzolar-S-metil na ativação de algumas respostas bioquímicas em planta de tomate (cv. Santa Cruz). Halos de inibição foram observados para os OEs de CI e CLa partir da concentração de $1 \%$.Os óleos essenciais de CI a uma concentração de $2.000 \mu \mathrm{L} \mathrm{L}^{-1}$ e CL na concentração de $1.500 \mu \mathrm{L} \mathrm{L}^{-1}$, bem como o ASM $0,2 \mathrm{~g}$ $\mathrm{L}^{-1}$ foram eficientes no controle da pinta bacteriana quando aplicados em uma única vez sete dias antes da inoculação do patógeno. O óleo essencial de CI e o ASM conferiram capacidade parcial de proteção em plantas de tomateiro desafiadas por Pst. Os óleos e o ASM também promoveram um aumento na quantidade de fenol total e lignificação da parede celular. Portanto por meio dos resultados obtidos neste trabalho foi demonstrado que existe um potencial uso de OEs no controle da pinta bacteriana do tomateiro, evidenciando a indução de resistência como o principal modo de ação atuante.

Palavras-chave: Pseudomonas syringae pv. tomato, doenças do tomateiro, controle alternativo de doenças, Solanum lycopersicum.

\section{ABSTRACT}

Silva, E.O.; Alves, E.; Ferreira, T.C.; Albuquerque, C.A.C. Essential oils in controlling bacterial speck and activation of biochemical responses in tomato plants. Summa Phytopathologica, v.43, n.3, p.212-217, 2017.

The aim of this study was to evaluate the effect of essential oils (EOs) of Cymbopogon sp. (Citronella - CI) and Cymbopogon citratus (Lemon grass$\mathrm{CL}$ ) in reducing bacterial speck (Pseudomonas syringae pv. tomato - Pst.) and activation of some biochemical defense responses in tomato plants. A test was performed in vitro to assess the presence or absence of Pst inhibition halo by Eos; an experiment was carried out in vivo to evaluate the best concentration of these two oils to control bacterial speck, and another experiment was conducted to evaluate the potential of these oils and acibenzolar-S-methyl (ASM) in the activation of some biochemical responses in the tomato plant (cv. Santa Cruz).
Inhibition halos were observed for EOs of CI and CL from the concentration of $1 \%$. Essential oils of $\mathrm{CI}$ at a concentration of $2,000 \mu \mathrm{L} \mathrm{L}^{-1}$ and $\mathrm{CL}$ at a concentration of $1,500 \mu \mathrm{L} \mathrm{L}^{-1}$, as well as ASM at $0.2 \mathrm{~g} \mathrm{~L}^{-1}$, were effective in controlling bacterial speck when applied once at seven days before pathogen inoculation. CI essential oil and ASM provided partial protection capacity in tomato plants challenged with Pst. In addition, the oils and ASM promoted an increase in the total amount of phenol and cell wall lignification. Therefore, this study demonstrated the potential use of EOs in controlling tomato bacterial speck, evidencing resistance induction as the main active mode of action.

Keywords: Pseudomonas syringae pv. tomato, tomato diseases, alternative disease control, Solanum lycopersicum.

Dentre as principais doenças da cultura do tomateiro está a pinta bacteriana. Seu agente etiológico é a Pseudomonas syringae pv. tomato (Pst) que foi relatada pela primeira vez no Brasil, em 1959, e a partir da década de 70, vem causando graves danos à cultura (8). A bactéria ataca toda a parte aérea das plantas, no qual é possível observar lesões escuras de 1-3 mm de diâmetro nas folhas, hastes e frutos, abortamento das flores e desfolha, queda dos cotilédones e retardamento do crescimento de mudas. Estes sintomas vêm causando uma queda na produção na ordem de 30\%, como já observado por Silva e Lopes (24). Além disso, soma-se a depreciação da qualidade do fruto e conseqüente redução na comercialização e este microrganismo pode sobreviver no solo cultivado como saprófita $(7,17)$.

O emprego de variedades resistentes seria a medida mais efetiva e econômica, entretanto isto nem sempre é possível, necessitando de métodos de controle adicionais além do controle cultural (6). O emprego de antibióticos para o controle de fitobactérias é questionado por diversas razões, além de não serem efetivos contra muitos patógenos, não possuem a aplicação permitida em muitos países, por poderem selecionar determinados patógenos resistentes ao produto (4). Já a aplicação de produtos químicos, como aqueles à base de cobre, pode resultar em fitotoxidez, necessitar de aplicações frequentes, causarem acúmulo no solo pelo uso contínuo, além do risco à saúde humana, uma vez que o tomate é colhido diariamente e muitas vezes não obedece aos períodos de carência do produto químico $(1,4)$.

Neste contexto, o emprego de óleos essenciais para o controle de doenças surge como uma nova alternativa visando à conservação do meio ambiente, a disponibilização de produtos de maior qualidade no mercado consumidor e a redução da aplicação de produtos químicos na lavoura $(1,6)$.

O emprego de óleos essenciais no manejo alternativo contra 
fitopatógenos tem sido relatado no controle de doenças fúngicas $(15,26,28)$ e bacterianas em plantas $(8,14)$. No caso de controle de bactérias, o modo pelo qual os óleos essenciais atuam pode ser atribuídos tanto à ação bactericida $(10,29)$ e quanto à indução de resistência (10). Como exemplo, pode-se citar o sucesso do controle de Pst por meio de diversos óleos essenciais aplicados em tomateiros descrito por Silva et al (23).

Como forma de estudar um método alternativo no manejo da pinta bacteriana do tomateiro bem como as melhores doses de OEs na sua redução, o presente trabalho teve como objetivos (i) avaliar a inibição in vitro de Pst por óleos essenciais; (ii) avaliar as melhores concentrações dos óleos essenciais de citronela e capim-limão para o controle da pinta bacteriana e (iii) avaliar o potencial do óleo essencial de citronela, capim-limão e do acibenzolar-S-metil na redução da pinta bacteriana e na ativação de algumas respostas bioquímicas de defesa de planta de tomate.

\section{MATERIAL E MÉTODOS}

\section{Local de execução dos experimentos}

O experimento in vitro foi realizado no laboratório de Microscopia Eletrônica pertencente ao Departamento de Fitopatologia (DFP). Os ensaios in vivo foram executados em casa de vegetação pertencente ao departamento de Agricultura (DAG), e posteriormente, as análises bioquímicas foram feitas no laboratório de Fisiologia do Parasitismo (DFP). As análises químicas dos óleos foram realizadas no laboratório de Análises em Química Orgânica, pertencente ao Departamento de Química (DQI). Ambos os laboratórios e instalações fazem parte da Universidade Federal de Lavras (Lavras - MG), e as análises foram realizadas no período entre Janeiro e Dezembro de 2014.

\section{Obtenção do inóculo}

O isolado de $P$. syringae pv. tomato (isolado UFV - 01) foi cedido da coleção de fitobactérias da Universidade Federal de Viçosa. Para utilização nos experimentos, o isolado Pst foi cultivado em meio Kado 523 (9) pelo método de estrias (11), por 24 horas à temperatura de $28^{\circ} \mathrm{C}$. Após este período, água esterilizada autoclavada foi adicionada à placa de Petri contendo o crescimento bacteriano e a concentração da suspensão foi ajustada em espectrofotômetro a $540 \mathrm{~nm}$ de absorbância,

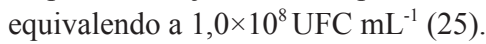

\section{Obtenção dos óleos essenciais utilizados no experimento}

Os óleos de CL e CI foram selecionados a partir das informações propostas por Silva. et al (23). Posteriormente os mesmos foram utilizados para o teste in vitro e para o controle da doença em cultivo protegido. Os óleos foram extraídos das folhas pela técnica de arraste a vapor, com a utilização de um aparelho tipo Clevenger modificado, e posteriormente foi feita sua análise quando ao composto marjoritário (2).

\section{Controle in vitro de Pst}

Este ensaio foi executado com OEs na concentração de $0,1 \%, 1 \%$ e $10 \%$, leite em pó (LP - 1\%) como emulsificante para os tratamentos à base de óleo, sulfato de estreptomicina $\left(25 \mathrm{mg} \mathrm{mL}^{-1}\right)$ e água esterilizada como testemunha. Discos de papel filtro autoclavados de $6 \mathrm{~mm}$ de diâmetro foram embebidos em $20 \mu \mathrm{L}$ de cada substância testada. Posteriormente foi realizada uma secagem à temperatura ambiente $\mathrm{e}$ colocados em placas de Petri com meio de cultura (9) contendo 200 $\mu \mathrm{L}$ da suspensão de Pst, na concentração de $5 \times 10^{8} \mathrm{UFC}_{\mathrm{mL}}{ }^{-1}$. Foram avaliadas a presença ou ausência de halos de inibição 48 horas após a incubação em câmara de crescimento a $28^{\circ} \mathrm{C}(10)$.

Ensaio in vivo: Doses de OEs no controle da pinta bacteriana em tomateiro

Foram utilizados os óleos essenciais de CI e CL em três concentrações $\left(2.000 \mu \mathrm{L} \mathrm{L}^{-1}, 1.500 \mu \mathrm{L} \mathrm{L}^{-1} \mathrm{e} 1.000 \mu \mathrm{L} \mathrm{L}^{-1}\right)$, o tratamento padrão de indução de resistência [acibenzolar-S-metil (ASM) - 0,2 mg $\mathrm{mL}^{-1}$ ] e água destilada esterilizada como controle.

Os OEs foram misturados em água de torneira e emulsificados com leite em pó ( $1 \%$ ) e, posteriormente, colocados em pulverizadores manuais. Os tratamentos foram aplicados 23 dias após a semeadura do tomateiro (cv. Santa Cruz), e após 7 dias ocorreu a inoculação do patógeno. As plantas foram previamente expostas à câmara úmida antes da inoculação com Pst, e depois mais $24 \mathrm{~h}$ em câmara úmida para obter um melhor sucesso na inoculação. Foram realizadas cinco avaliações, onde a primeira começou sete dias após a inoculação do patógeno e as posteriores a cada sete dias (10). A intensidade da doença foi avaliada visualmente utilizando um índice de doença (ID) de 0-3 com: $0=$ sem lesões, 1 = 2-5 manchas juntas ou espalhadas por toda a folha, 3 = mais de 11 manchas por folha (30). Foram calculadas as áreas abaixo da curva de progresso da severidade da doença de cada tratamento e a sua eficiência.

Avaliação da Indução de Resistência provocada pelos OEs em plantas de tomateiro

O experimento foi realizado com os óleos essenciais de CI e CL. Sementes de tomateiro da cultivar Santa Cruz Kada ${ }^{\circledR}$ (ISLA), foram semeadas em vasos de $3 \mathrm{~L}$ contendo como substrato a base da seguinte mistura: uma parte de substrato comercial Topstrato ${ }^{\circledR}$ e duas parte de solo de barranco. Houve também a adição em cada vaso, antes da semeadura, de 3 gramas de super simples e 2 gramas de NPK na proporção de 4:14:8.

Aos 15 dias de germinação, as plantas foram tratadas com os óleos essenciais de CI e CL a 0,1\%, acibenzolar-S-metil (ASM - 0,2 mg mL $\mathrm{mL}^{-1}$ ) e água destilada com e sem inoculação, respectivamente. A inoculação com Pst ocorreu quatro dias após o tratamento e as coletas no oitavo dia dias após a inoculação da Pst (10). As folhas foram coletadas e imediatamente congeladas em nitrogênio líquido em $-80^{\circ} \mathrm{C}$. Para o preparo do extrato protéico, o tecido foliar foi macerado, por meio de almofariz e pistilo, em $3 \mathrm{~mL}$ de tampão acetato de sódio $50 \mathrm{mM} \mathrm{pH}$ 5,2 contendo EDTA $0,1 \mathrm{mM}$, durante 5 minutos, em banho de gelo. Após a filtração em pano de trama fina, a solução foi centrifugada por 15 minutos e o sobrenadante recuperado. Todos os passos foram executados $4^{\circ} \mathrm{C}$. As proteínas solúveis contidas nos extratos foram aferidas com base no ensaio de Bradford (5), com uso de um padrão de albumina sérica bovina (BSA).

O conteúdo de lignina foi determinado pelo ensaio com ácido tioglicólico (TGA) (14), em que 0,2 g de tecidos meristemáticos foram incubados em acetona ( $85 \%$ ), por 48 horas e centrifugados por 15 minutos. O precipitado foi seco e incubado com $5 \mathrm{~mL}$ de

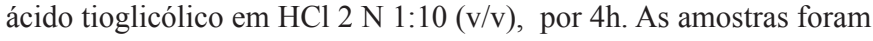
centrifugadas e o sobrenadante transferidos para novos tubos, nos quais receberam $200 \mu 1$ de $\mathrm{HCl} 10 \mathrm{~N}$. Após um banho de gelo por $4 \mathrm{~h}$ e uma centrifugação de $30 \mathrm{~min}$, o precipitado obtido foi homogeneizado em $5 \mathrm{~mL}$ de $\mathrm{NaOH}$ e a absorbância medida a $280 \mathrm{~nm}$. A quantidade de derivados TGA (lignina ácido-solúvel) formada foi medida pela comparação com uma curva padrão (0,01-0,1 mg éter 2-hidroxipropílico $\mathrm{mL}^{-1}$ ) e os valores expressos em micrograma de lignina por miligrama de matéria fresca ( $\mu \mathrm{g}$ mg-1 MF).

Já o conteúdo de fenol total foi determinado usando a metodologia 
descrita por Slinkard e Singleton (27), em que $150 \mu \mathrm{L}$ de extrato macerado foi acrescido de $150 \mu \mathrm{L}$ de Folin-Ciocalteau $0,25 \mathrm{~N}$ a 5 minutos na temperatura ambiente. Em seguida foram adicionados mais $150 \mu \mathrm{L}$ $\mathrm{Na} 2 \mathrm{CO} 31 \mathrm{M}$ e homogeneizado por mais $10 \mathrm{~min}$. Após esse tempo, foi acrescido mais $1 \mathrm{~mL}$ de água destilada deionizada, e posto a 1 hora à temperatura ambiente. Foi feito a leitura a $725 \mathrm{~nm}$ com base na curva de catecol, expresso em mg catecol $150 \mathrm{~g}^{-1}$ de tecido seco. Todas as determinações foram realizadas em triplicatas. Realizou-se a leitura a $725 \mathrm{~nm}$ com base na curva de catecol, expressa em mg de catecol por gramas de tecido seco (19).

\section{Analise Estatística}

$\mathrm{O}$ ensaio in vitro foi conduzido em delineamento inteiramente casualizados (DIC) com seis repetições. Os dois ensaios in vivo feitos em casa de vegetação foram conduzidos em delineamento de blocos casualizados (DBC), com três repetições e parcelas (vasos) constituídas de três plantas. Todos os experimentos foram realizados em triplicatas. Os dados foram submetidos a análises de variância em software estatístico Statistical Analysis System e as médias comparadas pelo teste de Scott-knott a 5\%.

\section{RESULTADOS E DISCUSSÃO}

Os óleos essenciais apresentaram as seguintes caracterizações químicas: citronela (citronelal - 29,98\%; citronelol - 14,34\%; geraniol - 18,2\%) e campim-limão (citral - 76\%). Estes compostos são reconhecidos por conterem propriedades antimicrobianas e repelentes $(13,20)$, como o citronelal e o citral, que atuam como eliciadores da produção de fitoalexinas (13).
Na concentração $0,1 \%$ não foi verificado halos de inibição por nenhum dos produtos estudados. Já a partir da concentração de $1 \%$ os óleos essenciais de citronela e capim-limão foram tóxicos à Pst e inibiram o crescimento do patógeno. O patógeno cresceu normalmente nos tratamentos compostos por água autoclavada (testemunha). Por outro lado, a testemunha positiva (sulfato de estreptomicina) inibiu o crescimento bacteriano.

O mecanismo de ação desses aldeídos envolve, principalmente, efeitos tóxicos à estrutura e à função da membrana celular. Como resultado do caráter lipofílico, esses aldeídos irão, preferencialmente, se deslocar da fase aquosa em direção às estruturas de membrana (22), e o acúmulo dos constituintes dos OEs na bicamada lipídica da membrana citoplasmática irão conferir a esta, uma característica de permeabilidade. Em bactérias, a permeabilização da membrana citoplasmática está associada à dissipação da força próton motiva, no que diz respeito à redução do pool de ATP, do pH interno e do potencial elétrico, e à perda de íons, como íons potássio e fosfato (3). Dessa forma, danos estruturais à membrana citoplasmática levam ao comprometimento de suas funções como barreira seletiva e local de ação enzimática e geração de energia (21). Sendo assim, quanto maior a concentração desse óleo essencial utilizada na solução, maior será a capacidade do mesmo de se deslocar em direção à membrana citoplasmática bacteriana, afetando assim seu funcionamento. Isso explica porque houve efeito inibitório direto dos óleos de CI e CL sobre o crescimento de Pst.

A atividade antimicrobiana in vitro de substâncias obtidas a partir de plantas medicinais vem sendo comprovada por alguns trabalhos, como Medice et al. (12), que verificaram que o óleo essencial de capim-limão a 1,0\% inibiu totalmente a germinação de urediniósporos de Phakopsora pachyrhizi. Além disso, Lucas et al. (10) verificaram inibição in vitro

60

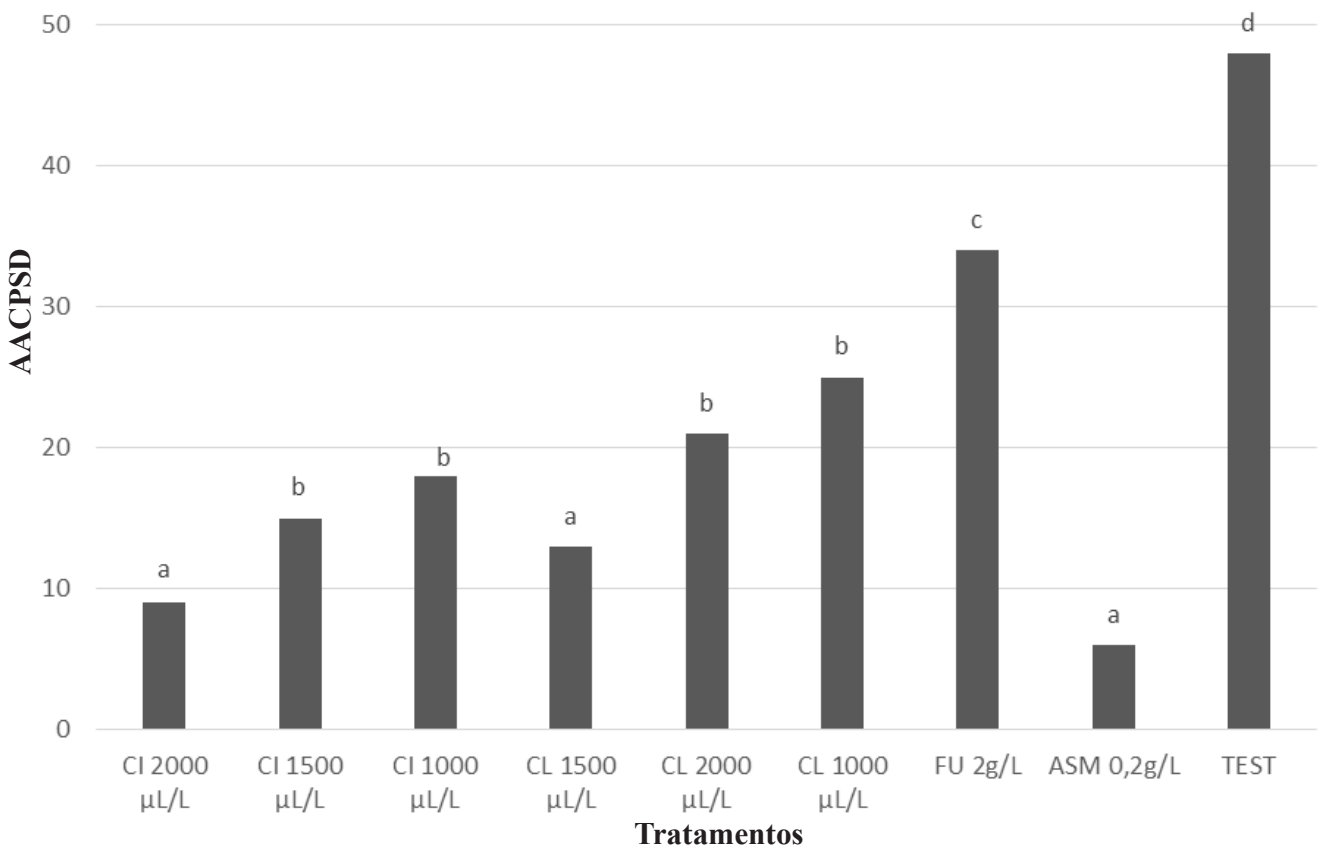

Figura 1 Área abaixo da curva de progresso da severidade da pinta bacteriana do tomateiro dos óleos essenciais de citronela (CI) e capim-limão (CL) nas concentrações de $1.000 \mu \mathrm{L} \mathrm{L}^{-1}, 1.500 \mu \mathrm{L} \mathrm{L}^{-1}$ e $2.000 \mu \mathrm{L} \mathrm{L}^{-1}$; acibenzolar-S-metil (ASM) e Recop ${ }^{\circledR}$ (FU), quando pulverizados somente uma vez antes da inoculação com Pst. As médias seguidas de mesma letra não diferem entre si, pelo teste de $\mathrm{Scott}-\mathrm{Knott}(\mathrm{p}<0,05)$. 
de Xanthomonas vesicatoria por óleos essenciais de citronela e capimlimão na concentração de $10 \%$. Silva et al. (23) também observaram a ação inibitória in vitro dos óleos essenciais de citronela e capim-limão a $10 \%$ sobre o crescimento de Pst.

Já para o segundo experimento, a utilização de CI e CL antes da inoculação, permitiu que fosse observado que os melhores tratamentos são: CI $2.000 \mu \mathrm{L} \mathrm{L}^{-1}, \mathrm{CL} 1.500 \mu \mathrm{L} \mathrm{L}^{-1}$ e CL $1.000 \mu \mathrm{L} \mathrm{L}^{-1}$, promovendo um controle de $75 \%, 56 \%$ e $47 \%$, respectivamente. Já os demais tratamentos promoveram eficiência intermediária (Figura1).

As plantas de tomateiro do experimento não apresentaram sinal de fitotoxidez devido à aplicação dos óleos essenciais em nenhuma concentração. Ao contrário de Medice et al. (12) que observaram sinais de fitotoxidez em plantas de soja tratadas com o óleo essencial de citronela utilizado a 1,0\%. Esta dose foi posteriormente reduzida para $0,5 \%$ e o problema não foi mais observado. Perina (16), trabalhando com os óleos essenciais de CI e CL nas concentrações de $0.1 \%, 0.2 \%$ e $0.05 \%$, constatou que plantas tratadas com a concentração mais baixa dos dois óleos essenciais possuem eficiência de controle inferior do que aquelas tratadas com concentrações mais altas em plantas de soja com oídio, fato esse também observado no presente trabalho.

Lucas et al. (10) observaram que a utilização dos óleos essenciais de citronela $2000 \mu \mathrm{LL}^{-1}$, capim limão $1000 \mu \mathrm{L} \mathrm{L}^{-1}$ e melaleuca $1500 \mu \mathrm{L}$ $\mathrm{L}^{-1}$ foram eficientes contra a mancha bacteriana do tomateiro quando aplicados somente sete dias antes da inoculação.

Ainda são poucos os trabalhos que utilizam diferentes doses de óleos essenciais em experimentos in vivo. Normalmente, a dosagem é pré-estabelecida de acordo com a literatura ou de acordo com testes in vitro, porém, na literatura são encontradas concentrações diversas e os testes in vitro nem sempre são representativos, pois os patógenos se comportam de forma diferente quando estão interagindo com as plantas e expostos às variáveis ambientais. Dessa forma, fica clara a necessidade de se determinar a concentração ideal para a utilização dos óleos essenciais, pois eles podem ser mais eficientes e mais viáveis economicamente.

No presente trabalho, foram apresentados resultados promissores na elucidação do modo de ação dos óleos essenciais de plantas medicinais. O teste in vitro mostrou que a $0,1 \%$ os óleos essenciais não promovem inibição do crescimento bacteriano, porém quando utilizados in vivo, essa concentração promove uma redução da severidade da doença (Figura 1).

Com relação à caracterização dos mecanismos bioquímicos de defesa avaliados, observou-se um aumento relativo do teor de lignina e do teor de fenol total (Figuras 2 e 3). Observou-se que a inoculação com Pst aumentou o teor de lignina e fenol total em folhas de tomateiro para todos os tratamentos, inclusive na testemunha. Esse comportamento é um indicativo de que a inoculação por si só, pode promover aumento no teor de lignina e fenol total da planta.

Plantas tratadas e inoculadas apresentaram pequenos incrementos de lignina e fenol total em relação às não inoculadas. Tal fenômeno também foi observado por Lucas et. al (10), em plantas de tomateiro quando inoculadas com bactérias do gênero Xanthomonas, o que, segundo tais autores, pode ter ocorrido em razão do reconhecimento do patógeno ao hospedeiro. A lignificação da parede celular é caracterizada como uma das reações desencadeadas pelo sistema de defesa de planta, no sentido de impedir a penetração ou de restringir a colonização dos tecidos por patógenos (18).

Desse modo, os óleos essenciais de citronela e capim-limão inibiram o crescimento in vitro de Pst, e in vivo, eles promoveram um aumento

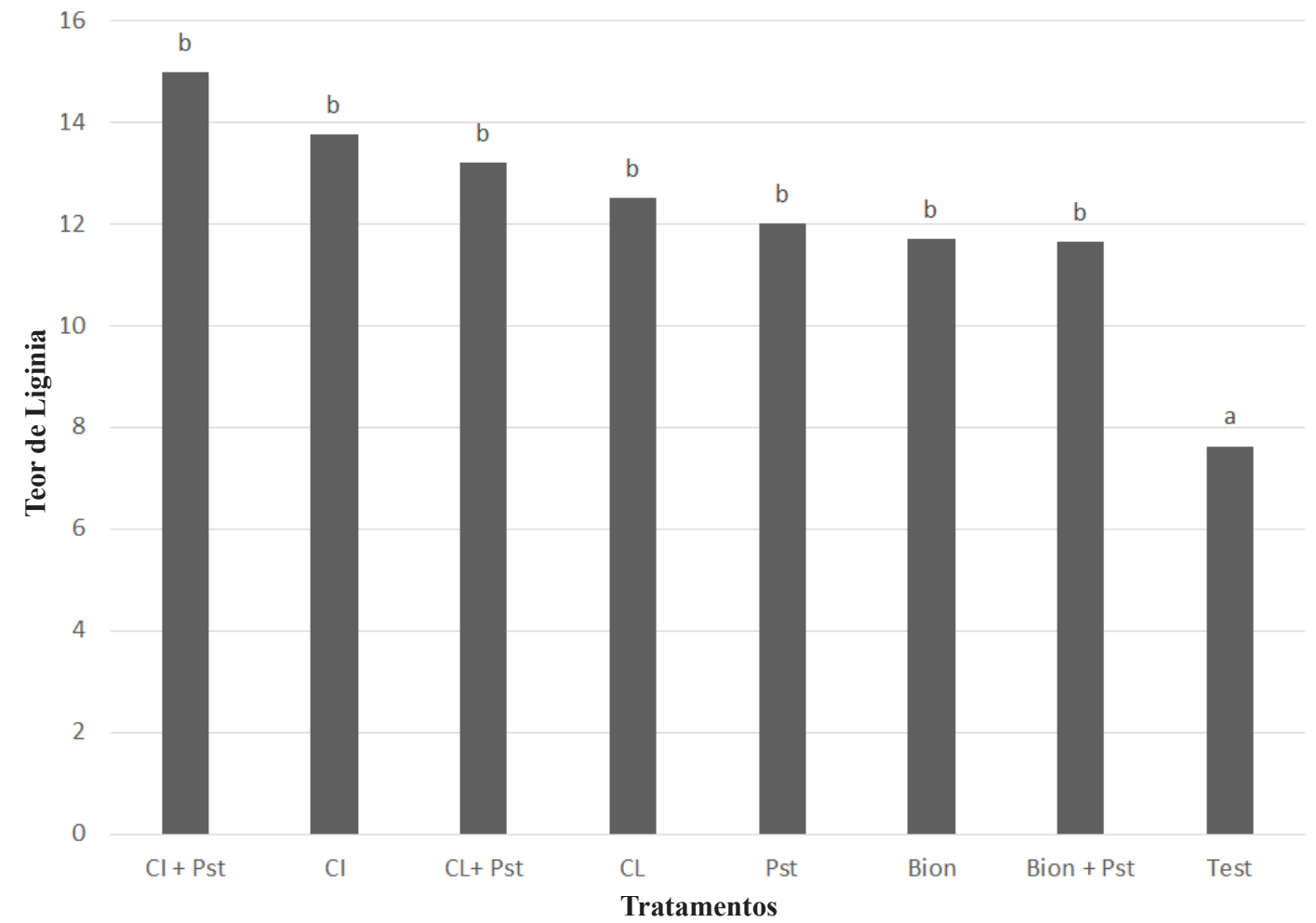

Figura 2 Teor de lignina solúvel ( $\mu \mathrm{g}$ mg-1 $\mathrm{MS}^{-1}$ ) em folhas de mudas de tomateiro, aos 12 dias após tratamentos com: ASM - acibenzolar-Smetil, óleo essencial citronela (CI) e óleo essencial de campim-limão (CL) comparado com a testemunha (Test.). A inoculação com Pseudomonas syrigae pv. tomato (Pst) ocorreu 4 dias após pulverização. Colunas com letras iguais não diferem entre si, de acordo com o teste de Scott-Knott, a $5 \%$ de probabilidade. 


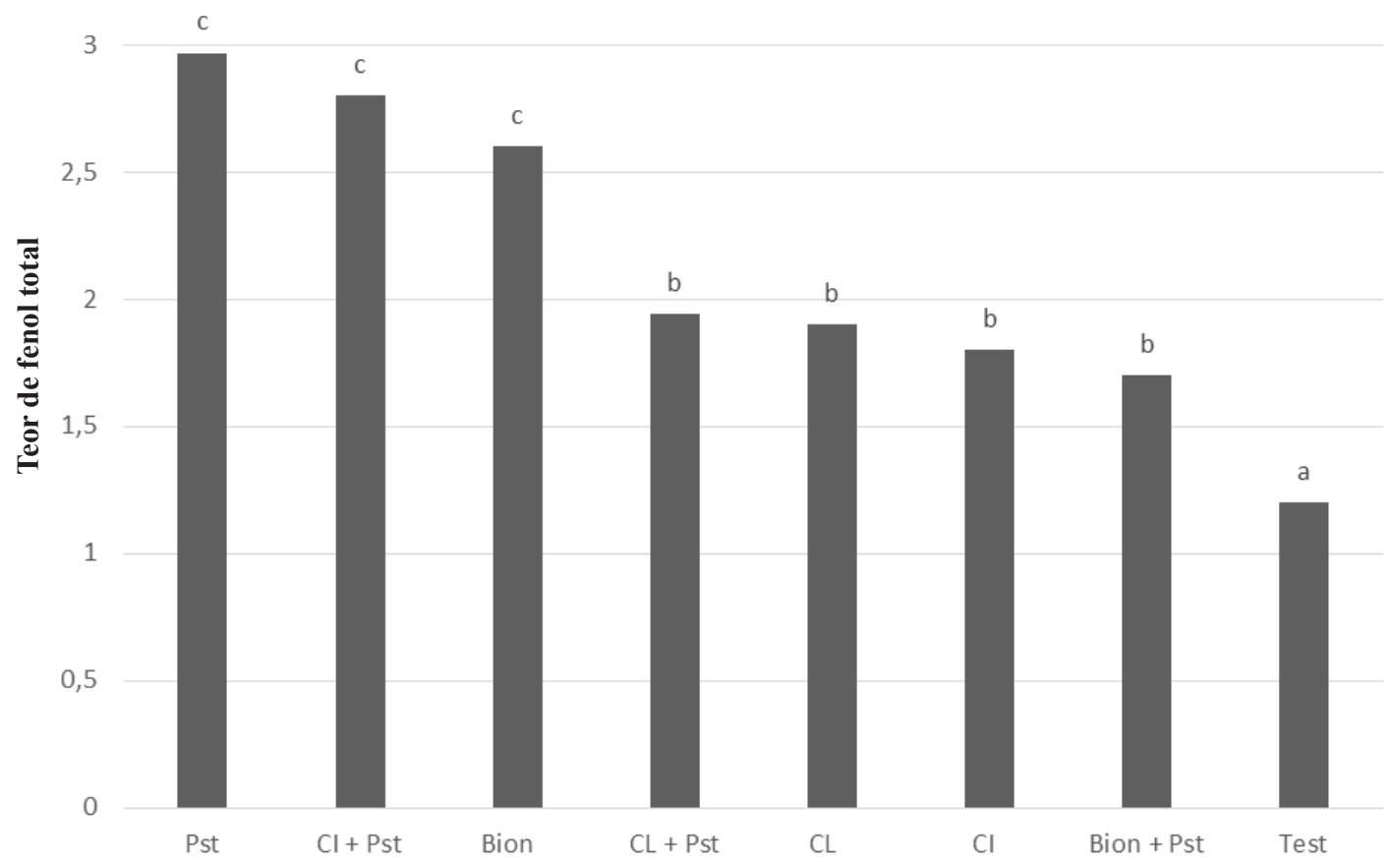

Tratamentos

Figura 3 Teor de fenol total (mg catecol mg-1 MS $\mathrm{MS}^{-1}$ em folhas de mudas 12 dias após tratamentos com: ASM - acibenzolar-S- metil, óleo essencial citronela (CI) e óleo essencial de capim-limão (CL) comparado com a testemunha (Test.). A inoculação com Pseudomonas syringae pv. tomato (Pst) ocorreu 4 dias após pulverização. Colunas com letras iguais não diferem entre si, de acordo com o teste de Scott-Knott, a 5\% de probabilidade.

no teor de lignina e fenol total das plantas de tomateiro, promovendo um controle positivo da pinta bacteriana.

\section{AGRADECIMENTOS}

Os autores gostariam de agradecer à CAPES e à FAPEMIG pela oportunidade e financiamento para realização do trabalho.

\section{REFERÊNCIAS}

1. ABREU, C.L. M. Controle de Alternaria Solani em (Lycopersicon esculentum) com óleos essenciais. 2006. 71p. Tese (Doutorado) - Universidade Estadual Paulista Júlio de Mesquita Filho, Botucatu.

2. ADAMS, R.P.; HATBE, M.; PARK, S.H.; DAFFORN, M.R.; Preliminary comparison of vetiver root essential oil from cleansed (bacteria- and fungus) versus non-cleansed (normal) vetiver plants. Biochem Syst Ecol, 32: 1137-1144, 2004.

3. BAKKALI, F.; AVERBECK, S.; INDAOMAR, M. Biological effects of essential oils: a review. Food and Chemical Toxicology, v.46, n.2, p.44675, 2008.

4. BALESTRA, G.M; HEYDARI, A.; CECCARELLI, D.; OVIDI, E.; QUATTRUCCI, A. Antibacterial effect of Allium sativum and Ficuscarica extracts on tomato bacterial pathogens. Crop Protection, v.28, p.807-811, 2009.

5. BRADFORD, M. M. A rapid and sensitive method for the quantification of microgram quantities of protein utilizing the principle of protein-dye binding. Analytical Biochemistry, New York, v. 72, n1/2, p. 248-254, May. 1976.

6. FRANZENER, G.; MARTINEZ-FRANZENER, A. da S.; STANGARLIN, J.R.; CZEPAK, M. P.; SCHWAN-ESTRADA, K.R.F.; CRUZ, M. E. S. Atividades antibacteriana, antifúngica e indutora de fitoalexinas de hidrolatos de plantas medicinais. Semina: CiênciasAgrárias, v.28, p.29-38, 2007.

7. HERMAN, M.A.B.; DAVIDSON, J.K.; SMART,C.D. Induction of plant defense gene expression by plant activators and Pseudomonas syringaepv. tomato in greenhouse-grown tomatos. Phytopathology, v.98, p.1226-1232, 2008.

8. JUNIOR, V.A. M. Doenças bacterianas em tomateiro: etiologia e controle. Instituto Agronômico, Campinas, SP, 2004. Disponível em: http://www. feagri.unicamp.br/tomates/pdfs/doebacter.pdf. Acesso em: 07 abr. 2015.

9. KADO, C.I.; HESKETT, M.G. Selective media for isolation of Agrobacterium, Corynebacterium, Erwinia, Pseudomonas and Xanthomonas. Phytopathology, v. 60, p.96-97, 1970.

10. LUCAS, C.G.; ALVES, E.; PEREIRA, R.B.; PERINA, F.J.; SOUZA, R.M. Antibacterial activity of essential oils on Xanthomonas vesicatoria and control of bacterial spot in tomato. Pesquisa Agropecuária Brasileira, v.47, p.351-359, 2012.

11. MARIANO, R. L. R.; SILVEIRA, E. B.; ASSIS, S. M. P.; GOMES, A. M. A. Identificação de bactérias fitopatogênicas. In: MARIANO, R. L. R.; SILVEIRA, E. B. (Eds.). Manual de práticas em fitobacteriologia. 2a. ed. Recife: Universidade Federal Rural de Pernambuco, 2005. p. 67-111.

12. MEDICE, R.; ALVES, E.; ASSIS, R. T. de; MAGNO JUNIOR,M.R.; LOPES, E. A. das G. L. Óleos essenciais no controle da ferrugem asiática da soja Phakopsora pachyrhiziSyd. \& P. Syd. Ciência e Agrotecnologia, v. 31, p.83-89, 2007.

13. MOREIRA, C.G.A.; SCHWAN-ESTRADA, K.R.F.; BONALDO, S.M.; STANGARLIN, J.R.; CRUZ, M.E.S. Caracterização parcial de frações obtidas de extratos de Cymbopogon nardus com atividade elicitora de fitoalexinas em sorgo e soja e efeito sobre Colletotrichum lagenarium. Summa Phytopathologica, Jaguariúna, v.34, n.4, p.332-337, out/dez, 2008.

14. MONTIES, B. Lignins. In: DEY, P. M.; HARBORNE, J. B. (Ed). Methods in plant biochemistry. New York: Academic , 1989. p. 113-158.

15. PASSOS, J.L.; BARBOSA, L.C.A.; DEMUNER, A.J.; ALVARENGA, E.S.; SILVA, C.M. da; BARRETO, R.W. Chemical Characterization of Volatile Compounds of Lantana camara $\mathrm{L}$. and L. radula $\mathrm{S}$ w. and Their Antifungal Activity. Molecules, v.17, p.11447-11455, 2012.

16. PERINA, F. J. Avaliação de óleos essenciais e solução de leite no controle do oídio da soja (Microsphaera diffusa). 2008. 32p. Monografia (Gradua- 
ção emAgronomia) - Universidade Federal de Lavras, Lavras.

17. PIETRARELLI, G.B.L.; VARVARO, L. Effects of simulated rain on Pseudomonas syringaepv. tomato populations on tomato plants. Journal of Plant Pathology, v.88, p.245-251, 2006.

18. RESENDE, M. L. V. de; COSTA, J. C. B.; CAVALCANTI, F. R.; RIBEIRO JÚNIOR, P. M.; CAMILO, F. R. Seleção de extratos vegetais para indução de resistência e ativação de respostas de defesa em cacaueiro contra a vassoura-de-bruxa. Fitopatologia Brasileira, v. 32, n. 3, p. 213-221, maio 2007.

19. RODRIGUES, F.A.; JURICK II, W.M.; DATNOFF, L.E.; JONES, J.B.; ROLLINS, J.A. Silicon influences cytological and molecular events in compatible and incompatible rice-Magnaporthe grisea interactions. Physiological and Molecular Plant Pathology, London, v. 66, p.144-159, 2005

20. SCHERER, R.;WAGNER, R.; DUARTE, M.C.T.; GODOY, H.T. Composição e atividade antioxidante e antimicrobiana dos óleos essenciais de cravo-da-india, citronela e palmarosa. Revista Brasileira de Plantas Medicinais, Botucatu, v.11, n.4, p.442-449, 2009.

21. SIKKEMA, J.; BONT, J.A.M.; POOLMAN, B. Interactions of cyclic hydrocarbons with biological membranes. Journal of Biological Chemistry, v.269, n.11, p.8022-8, 1994.

22. SIKKEMA, J.; BONT, J.A.M.; POOLMAN, B. Mechanisms of membrane toxicity of hydrocarbons. Microbiological Reviews, v.59, n.2, p.201-22, 1995.

23. SILVA, É. O.; MARTINS, S.J.; ALVES, E. Essential oils for the control of bacterial speack in tomato crop. African Journal of Agricultural Re- search, 9 (34), 2624-2629, 2014.

24. SILVA, V. L.; LOPES, C. A. Populações epifiticas de Pseudomonas syringae pv. tomato em cultivo comercial de tomateiro industrial. Fitopatologia Brasileira, Brasília, v.20, p.179-183, 1995.

25. SILVA, J.R.C., SOUZA, R.M., SACARONE, A.B., SILVA, L.H.C.P., CASTRO, A.M.S. Bactérias endofíticas no controle e inibição in vitro de Pseudomonas syringae pv. tomato, agente da pinta bacteriana do tomateiro. Ciência e Agrotecnologia, v.32, , p.1062-1072, 2008.

26. SILVA, A.C.; DE SOUZA, P.E.; PINTO, J.E.B.P.; DA SILVA, B.M.; AMARAL, D.C.; CARVALHO, E.A. Essential oils for preventative treatment and control of Asian soybean rust. European Journal of Plant Pathology. v.134, p.865-871, 2012.

27. Slinkard K, Singleton VL. Total phenol analysis: automation and comparison with manual methods. Am J Enol Viticult. 1977;28:49-55.

28. VELOSO, R.A.; CASTRO, H.G. de; CARDOSO, D.P.; SANTOS, G.R. dos; BARBOSA, L.C.de A.; SILVA, C.P. da. Composição e fungitoxicidade do óleo essencial de capim citronela em função da adubação orgânica. Pesquisa Agropecuária Brasileira, v.47, p.1707-1713, 2012.

29. VIGO, S.C.; MARINGONI, A.C.; CÂMARA, R. de C., LIMA, G.P.P. Ação de tinturas e óleos essenciais de planta medicinais sobre o crestamento bacteriano comum do feijoeiro e na produção de proteínas de indução de resistência. Summa phytopathologica, v.35, p.293-304, 2009.

30. YUNIS, H.; BASHAN, Y.; Okon, Y.; HENIS, Y. Two sources of resistance to bacterial speck of tomato caused by Pseudomonas tomato. Plant Disease, v.64, p.851-852, 1980. 